MILESTONE 4

\title{
Making antibodies
} work

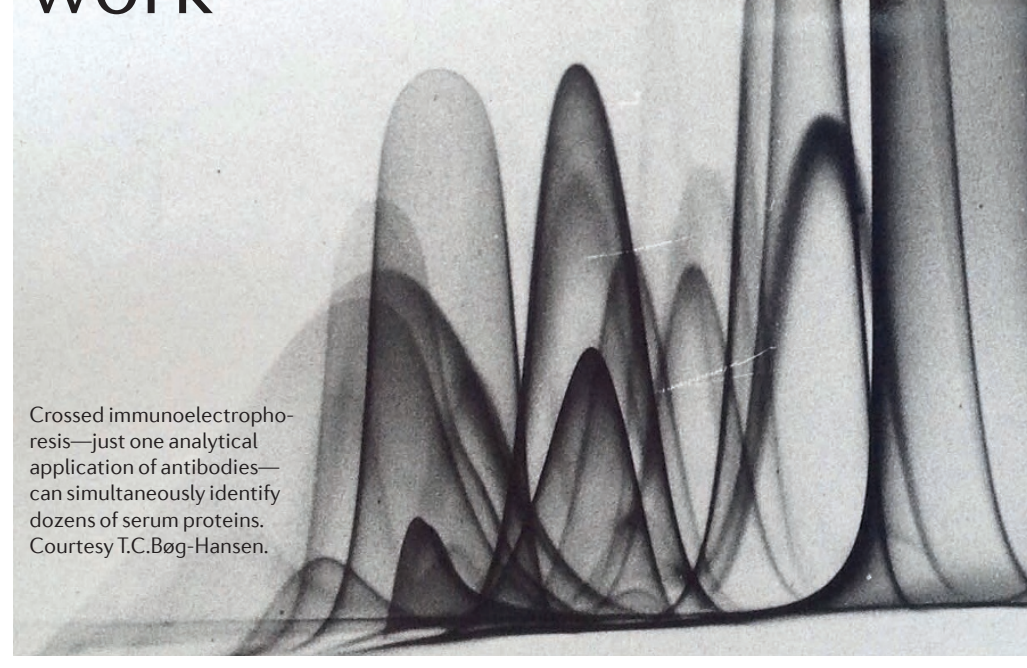

Because antibodies are able to specifically bind target molecules, the possibility of their having an analytical application was recognized early on. Robin Coombs, Arthur Mourant and Robert Race, working for the UK's Medical Research Council emergency blood-transfusion service, were keen to determine whether specific antibodies, such as those binding to red blood cells in autoimmune hemolytic anemia, were present in the human body. However, ambiguous results were often obtained with the existing methodology. In 1945 they described how to use anti-human-immunoglobulin serum to agglutinate red blood cells that had antibody bound to their cell surface. This enabled them to better distinguish whether antibodies to $\mathrm{Rh}$ factor were present in the blood. The ability to detect such antibodies had a practical application, as the presence of antibodies could be indicative of the susceptibly of newborn babies to hemolytic disease. The assay developed was a forerunner to the Coombs tests that are used to this day.

Another major advance in the technical application of antibodies came in 1960. Rosalyn Yalow and Solomon Berson developed a system using antibodies to quantify insulin present in blood plasma. The principle behind this was the competition between the binding of antibodies to endogenous insulin versus their binding to radioactive insulin. This radioimmunoassay was used to measure insulin present in the blood and provided greater sensitivity than that of previous approaches. It was subsequently applied to a multitude of serum antigens. The importance of the radioimmunoassay was recognized by a Nobel Prize awarded to Rosalyn Yalow in 1977; unfortunately, Solomon Berson had already died and so was unable to be a co-recipient.

In 1971 researchers described replacing the radioactive label with components detectable in alternative ways. Bauke van Weeman and Anton Schuurs chose to conjugate their molecule of interest (human chorionic gonadotrophin) with the enzyme horseradish peroxidase. The antibody thus bound a molecule that would change the color of a substrate when oxidized by horseradish peroxidase. They used this system to assay the amount of human chorionic gonadotrophin in the urine of women, thereby identifying those who were pregnant. The general principle behind this assay remains the basis of many pregnancy-testing kits today. Concurrently, Eva Engvall, a graduate student in Stockholm, and Peter Perlmann, her advisor, performed a similar assay but used antibody

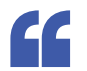

monoclonal antibodies... have had a truly transformative effect on laboratory sciences.

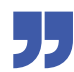

conjugated to the enzyme alkaline phosphatase. They named their assay the 'enzyme-linked immunosorbent assay', which resulted in the catchy acronym 'ELISA' In addition to its application in the detection and quantification of serum components, ELISAs are routinely used to detect viral infections, such as infection with human immunodeficiency virus, and the technique remains a mainstay of laboratories around the world.

In addition to detecting the tagging of antibodies to molecules or cells of interest, it was clearly desirable to be able to separate the tagged components. This was achieved in 1979 by David Parks, Virginia Bryan, Vernon Oi and Leonard Herzenberg, who used the newly invented fluorescence-activated cell sorter. The light-scattering and fluorescent properties of the cells enabled cells bound with antigen-coupled microspheres to be distinguished and directed into alternative collection pots, thus facilitating phenotypic separation, description and categorization.

Since the pioneering work of César Milstein and Georges J. F. Köhler (MILESTONE 9) there have been innumerable applications and refinements to the application of monoclonal antibodies. Immunohistochemistry, immunofluorescence, immunoprecipitation, immunoblot analysis, Ouchterlony double immunodiffusion, radial immunodiffusion and rocket immunoelectrophoresis are additional techniques dependent on the use of antibodies that have been implemented widely across the biological sciences. Thanks to their specific binding and the possibility for investigators to select the target of choice, monoclonal antibodies have proven to be an indispensable research and analytical tool that have had a truly transformative effect on clinical and laboratory sciences.

Katharine Barnes Managing Editor, Nature Protocols

ORIGINAL RESEARCH PAPERS Coombs, R. R. A. et al. A new test for the detection of weak and "incomplete" Rh agglutinins. Br. J. Exp. Pathol. 26, 255-266 (1945) |Yalow, R. S. \& Berson, S. A. Immunoassay of endogenous plasma insulin in man. J. Clin. Invest. 39, 1157-1175 (1960) | Van Weemen, B. K. \& Schuurs, A. H. W. M. Immunoassay using antigen-enzyme conjugates. FEBS Lett. 15, 232-236 (1971)|Engvall, E. \& Perlmann, P. Enzyme-linked immunosorbent assay (ELISA) quantitative assay of immunoglobulin G. Immunochemistry 8, 871-874 (1971)| Parks, D. R. et al. Antigen-specific identification and cloning of hybridomas with a fluorescence-activated cell sorter. Proc. Natl. Acad. Sci. 76, 1962-1966 (1979) 